وضعيت يتاسيم در خاكهاى تحت كشت گندم و ارتباط آن با پتاسيم دانه در منطقه داراب، جنوب شرقى استان فارس

\author{
مهدى نجفى قيرى
}

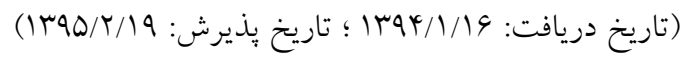

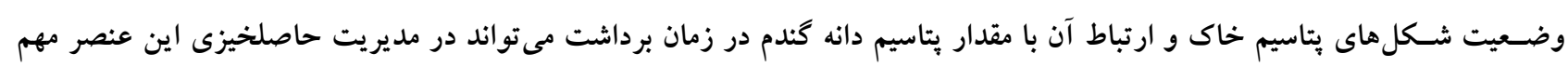

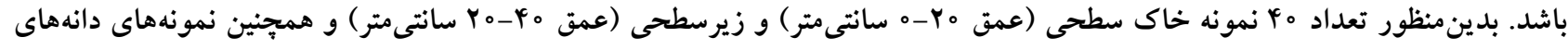

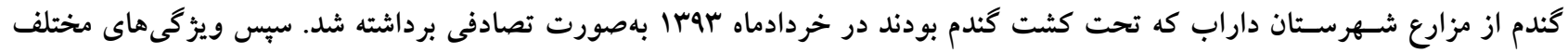

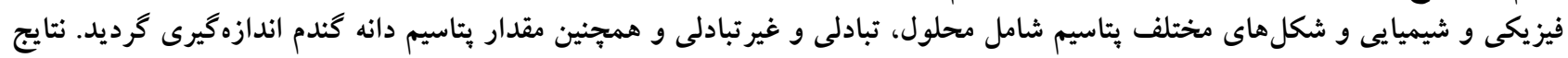

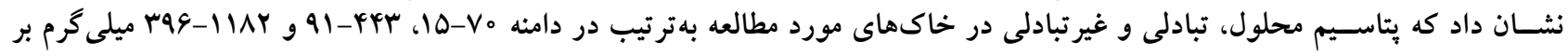

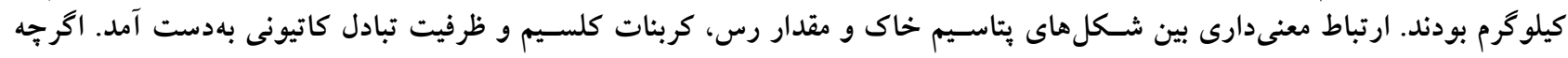

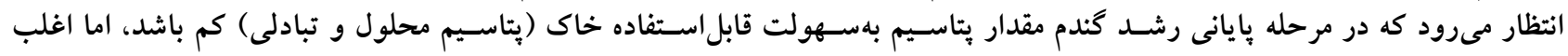

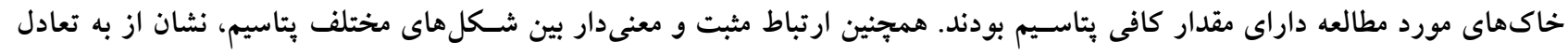

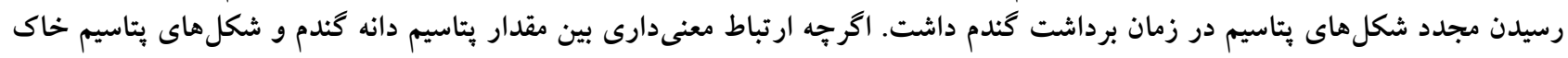

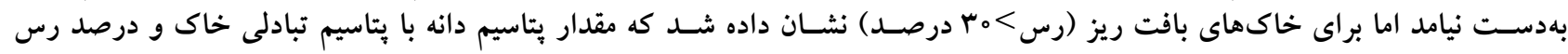

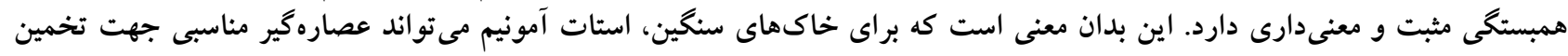

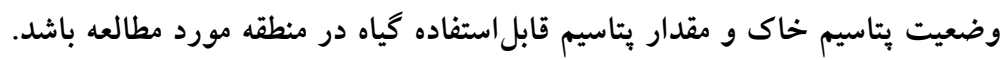
وازههاى كليدى: استات آمونيم؛ خاكهاى آهكى؛ يتاسيم تبادلى؛ پتاسيم دانه كُندم

\footnotetext{
ا. بخش مرتع و آبخيزدارى، دانشكده كشاورزى و منابع طبيعى داراب، دانشكاه شيراز

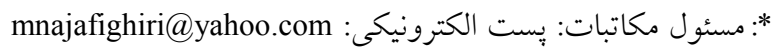


متعددى مانند كانىشـناسسى بخش رس و سـيلت خاك، تكامل

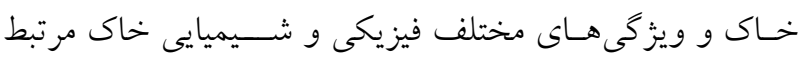

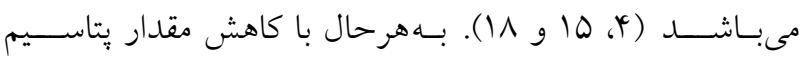

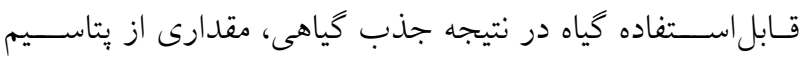

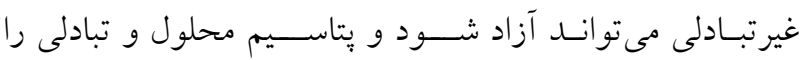

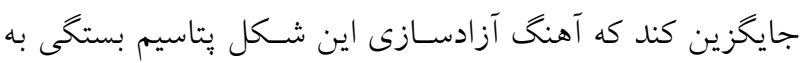

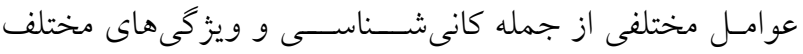
فيزيكى و شيميايى خاكها دارد (19 و IV).

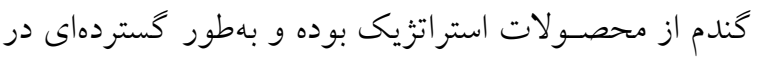
استان فارس و بهخصوص داراب كشت مىشود. تحقيقات نشان

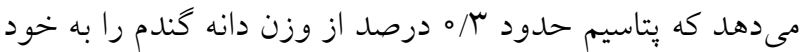
اختصـاص مىدهد و از اين نظر پِس از نيتروزن مهمترين عنصر غذايى اسـت كه به مقدار زياد توسط كياه جذب مىشود (TV).

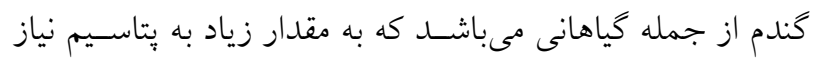

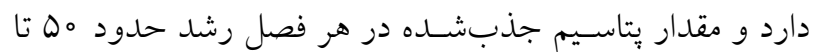

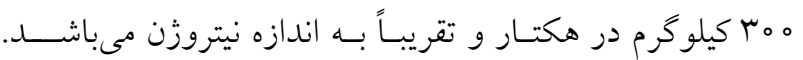

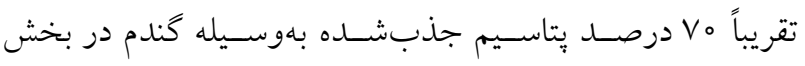

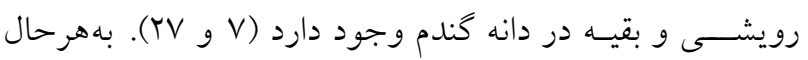

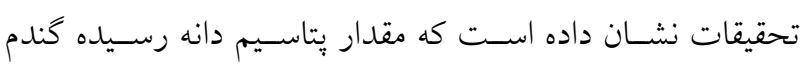

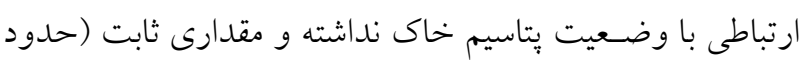
r/ه

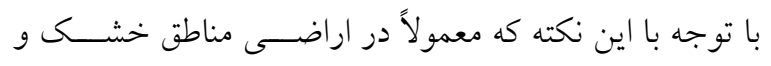

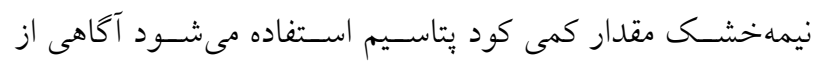
وضسيت بتاسيم خاك و تغييراتى كه در شكل هاى مختلف بِّاسيم

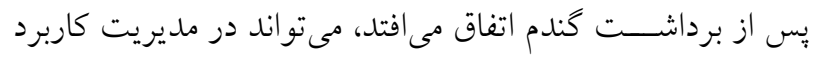

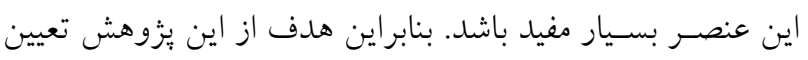

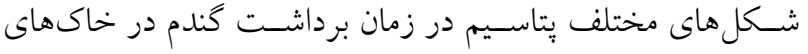
شـهرستان داراب، تعيين عوامل خاكى مؤثر بر مقدار بتاسيم خاك

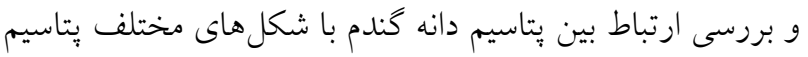
خـاك مى بـاشــــ. نتايج اين ثروهش مى تواند در مديريت كاربرد

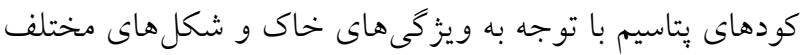

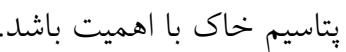

يتاسـيم بهطور متوسط م/9 درصد وزنى يوسته زمين را تشكيل

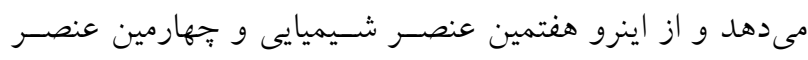

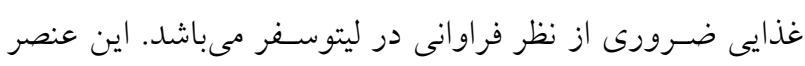

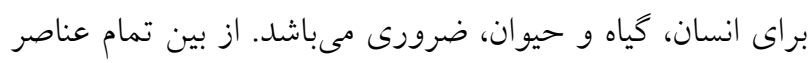

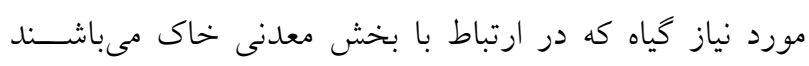

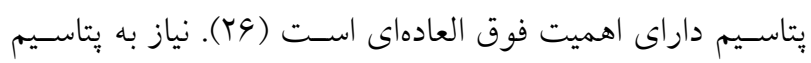

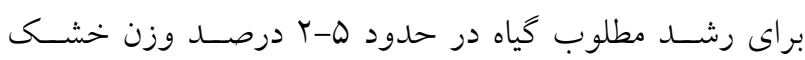

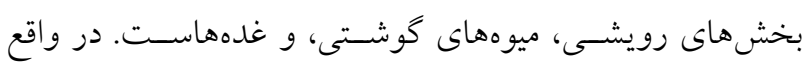

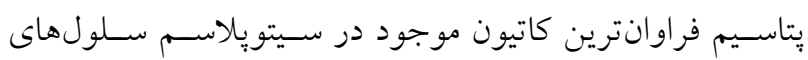

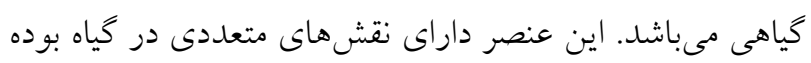

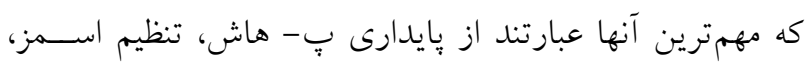

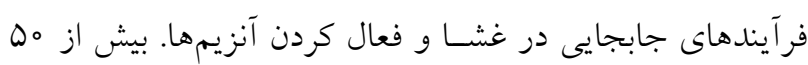

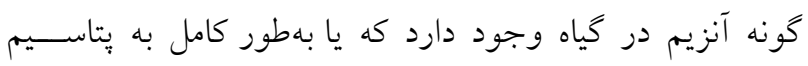

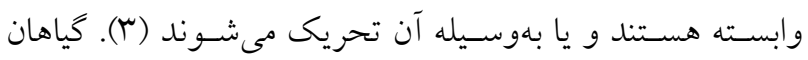

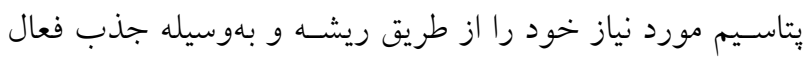
از محلول خاك به دست مى آورند.

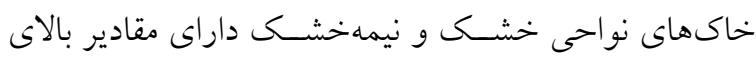

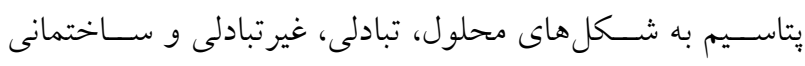

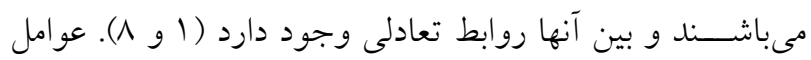

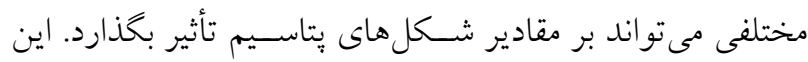
عوامل شـامل خصوصيات فيزيكى و شيميايى خاك مانند مقدار

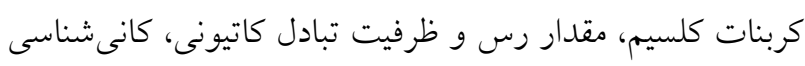

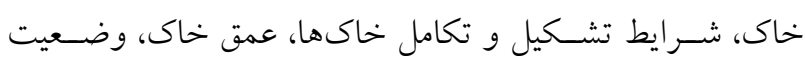

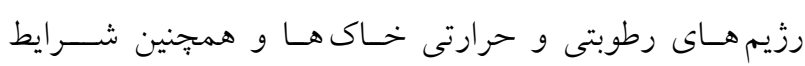

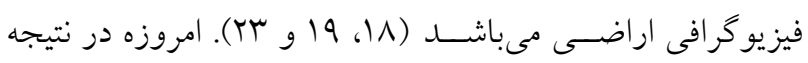

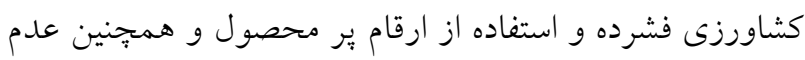

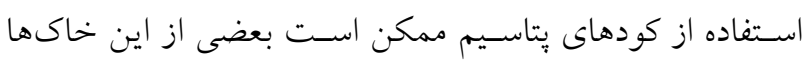

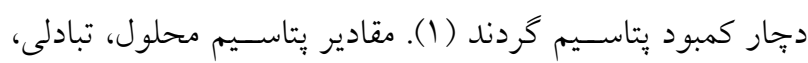

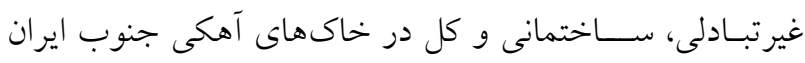
بسه ترتيـب، مو

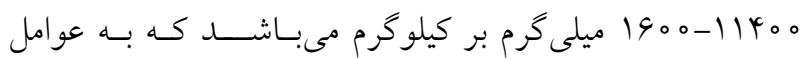


درصـد اشـباع پِتاسـيم نمونهها با تقعسيم مقدار يتاسيم تبادلى به ظرفيت تبادل كاتيونى بر حسب درصد بهدست آمد. نمونسههـاى دانـه كنــدم نيز يس از جدا كردن از كاه و كلش آسيابشده و در كوره الكتريكى در دماى •هه درجه سانتى گراد خاكستر كرديد. خاكستر حاصـل با اسـيد كلريدريك دو مولار عصسارهگيرى و ســس غلظت يتاسيم در آن با دستخاه شعلهسنج

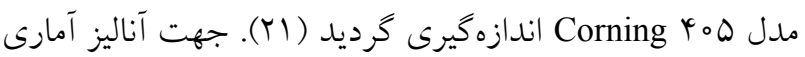
Microsoft Office Excel و SPSS r. نمونها از نرمافزارهاى

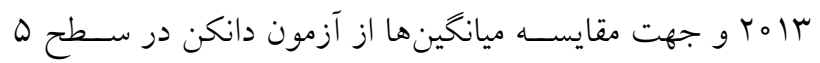
درصد معنى دارى استفاده شد.

\section{نتايج و بحث} الف) بررسى ويزگگىهاى خاكهاى مورد مطالعه منطقه مورد مطالعه اخر جهه داراى وسـعت كمى اسـت اما داراى خاكهاى متنوعى از نظر ويزّكى هاى فيزيكى و شيميايى مىباشد (جدول (1). مقدار رس در خاكهاى سطحى از ها تا ه ه درصد متغير مىباشـد. مقدار شـن نيز در خاكهاى سـطحى متنوع و از

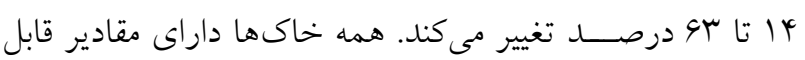

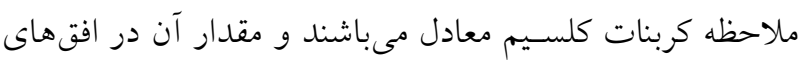
سـحى از وب تا بو درصد و در خاكهاى زيرسطحى از ^ب تا DV درصـــ متغير مىباشـــ. ظرفيت تبادل كاتيونى در خاكهاى

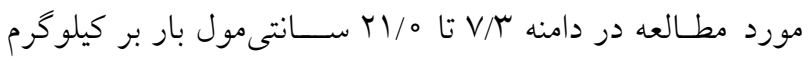

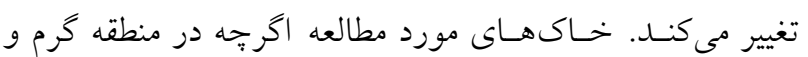

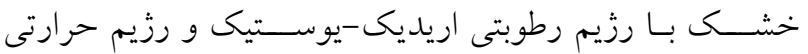

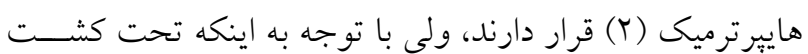
كُندم آبى بودند داراى دامنه باريكترى از شورى بوده و قابليت هدايت الكتريكى در خاكهاى سطحى كمتر از أ دسىزيمنس بر متر و در خاكهاى زيرسـطحى كمتر از ه/ه دسسىزيمنس بر متر مىباشـد. البته براساس طبقهبندى ماس و هافمن ( ا ) خندم جزء گيـاهان مقاوم به شــورى بوده و با توجه به مقدار قابليت هدايت الكتريكى خاكهاى مورد مطالعه، بهنظر

\section{مواد و روشها}

ابتدا تعداد هY مزرعه كندم (تحت كشت رقم جّمران) در منطقه داراب بهصــورت تصــادفى انتخاب و نمونههاى مركب از ينج

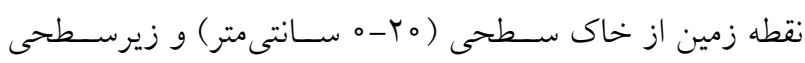

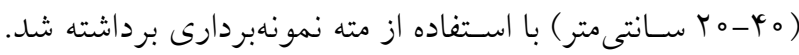
منطقه داراب (جنوب شــرق اســان فارس) در محدوده طول

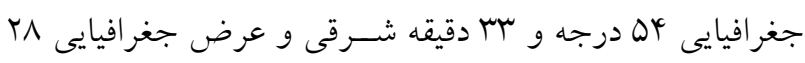

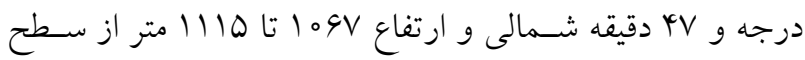

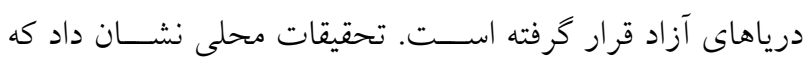
مصـرف كودهاى يتاسـيم در بيشـتر مزارع مورد مطالعه بهطور متوسط كمتر از •D كيلو گرم در هكتار در سال بوده است. تعداد

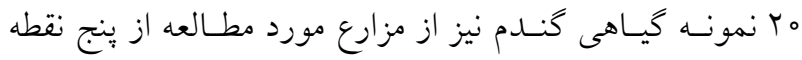
جهـت انــازه گيرى درصــــ يتـاســـيم دانه برداشــت كرديد. نمونهبردارى در زمان برداشـت يا نزديك به برداشـت گُندم در خردادماه سوسا صــورت كرفت (مرحله رســيدن كامل دانه).

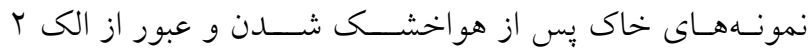
ميلى مترى جهت اندازه گيرى ويزّى هاى فيزيكى و شــيميايى و

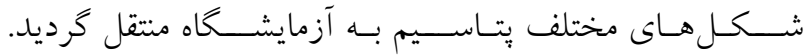
آزمايشهاى مختلف فيزيكى و شــيميايى شـــامل توزيع اندازه ذرات خاك ( (T)، بֶ-هاش (Y)، كربنات كلسـيم معادل (YT)،

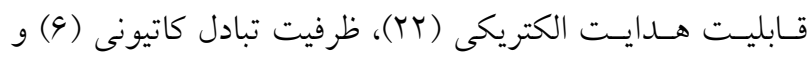
مقدار كربن آلى (Yo) روى نمونهها صـورت گرفت. اندازهيرى شـكل هاى مختلف يتاسـيم شامل محلول، تبادلى و غير تبادلى به روش هلمك و اسياركز (9) انجام شد. يتاسيم محلول در عصاره

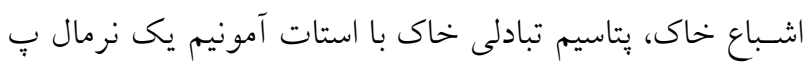
- هاش V و يتاسيم غيرتبادلى با اسيد نيتريك يك نرمال جوشان اندازه گيرى گرديدند (9). غلظت بتاسـيم در عصارهها با استفاده از دسـتخاه شـعله سـنج مدل هـ Corning اندازه گيرى گرديد. يتاسـيم تبادلى با كسـر مقدار بتاسـيم اسـتخر اج شــه بهوسـيله استات آمونيم از يتاسيم محلول و يتاسيم غيرتبادلى با كسر مقدار يتاسـيم اسـتخراج شـده بهوسـيله اسيد نيتريك از استات آمونيم محاسبه گرديد. همه اندازهيرىها در سه تكرار صورت گرفت. 
جدول ا. ويزّكىهاى فيزيكى و شيميايى و مقادير شكلهاى يتاسيم در خاكهاى مورد مطالعه

\begin{tabular}{|c|c|c|c|c|c|c|}
\hline \multicolumn{3}{|c|}{ خاى زيرسطحى ( } & \multicolumn{3}{|c|}{ خاى سطحى (0_o بانتى متر) } & \multirow{2}{*}{ ويز كى هاى خاى } \\
\hline انحر اف معيار & ميانخين & مامنه & انحر اف معيار & ميانخين & دامنه & \\
\hline IT & rya & $10-0 \varphi$ & 11 & سـa & $10-\Delta Y$ & رس، ٪٪ \\
\hline 9 & rya & Y०-ఎ० & $\wedge$ & $r \Delta^{b}$ & Y०-ఎ० & 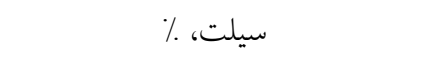 \\
\hline 19 & rra & $\mid k-q K$ & 19 & rra & $\mid y-94$ & 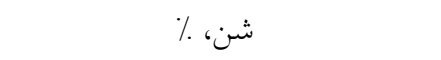 \\
\hline 0 & rqa & ऍへ-QV & 4 & $\varphi \varphi \mathrm{a}$ & MG-GY & كربنات كلسيم معادل، . \\
\hline$\circ / 10$ & $V / 9 \wedge^{\mathrm{a}}$ & $V / \Delta \Lambda-\Lambda / \mu Y$ &.$/ 14$ & $\mathrm{~V} / 9 \mathrm{~V}^{\mathrm{a}}$ & $V / 9 \circ-\Lambda / T)$ & \\
\hline $1 / 9$ & $1 / Y^{\mathrm{a}}$ & $\circ / \Gamma-\Delta / \Delta$ & $1 / 1$ & $1 / 0^{a}$ & $\circ \mu-r / 1$ & قابليت هدايت الكتريكى، 'dS m \\
\hline$r / 9$ & $11 / 1 \mathrm{a}$ & $V / 0-r \circ / r$ & $r / \mathrm{V}$ & $11 / \mathrm{r}^{\mathrm{a}}$ & $V / r-r I / 0$ & ظرفيت تبادل كاتيونى، 'cmol(+) kg \\
\hline 9 & $r q^{a}$ & $r_{0-G \circ}$ & 14 & kra & $10-V \circ$ & يتاسيم محلول، '- mg kg \\
\hline va & $r \mid T^{\mathrm{b}}$ & $q 1-r q 4$ & $\wedge \vee$ & rrga & qV-tert & يتاسيم تبادلى، 'mg kg \\
\hline r०Q & $v \notin I^{a}$ & raq-1109 & $r \circ r$ & $\vee \Delta \wedge^{\mathrm{a}}$ & YYA-I1Nr & يتاسيم غيرتبادلى، 'ي kg kg \\
\hline $1 / 9$ & $Q / \circ a$ & $Y / V-\Lambda / q$ & $1 / 9$ & $Q / Y^{a}$ & $r / 9-9 / r$ & اشباع يتاسيم، ٪" \\
\hline
\end{tabular}

مىباشد كه بيان كردند يتاسيم محلول در خاكهاى استان فارس مى تواند تا هوب ميلى گرم بر كيلو گرم باشـــ كه البته مقادير بالاتر

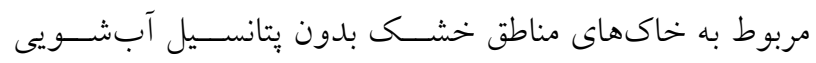

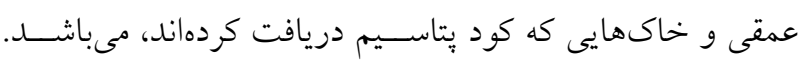
بههرحال تفاوت معنى دارى بين يتاسيم محلول در خاى سطحى و زيرسطحى وجود ندارد. ارتباط مثبت و معنى دارى بين يتاسيم محلول و مقـدار رس و ظرفيـت تبـادل كـاتيونى بهدســت آمد

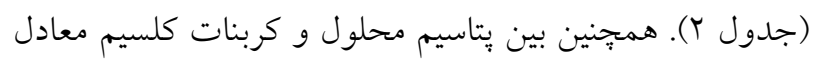
ارتباط منفى و معنىدارى وجود داشت. اكر تجه انتظار مىرود كه ارتباط منفى بين مقدار يتاسيم محلول و درصد رس وجود داشته باشـــد و در واقع با افزايش مقدار رس و ظرفيت تبادل كاتيونى، يونهاى يتاسيم تمايل به جذب روى سطوح تبادلى داشته باشند اما شــايد ارتباط مثبت بهدسـت آمده در اين مطالعه را بتوان به ممانعت رس از آبشويى يتاسيم محلول و ساير يونها در نتيجه كاهش نفوذيذيرى خاك دانسـت. وجود ارتباط مثبت بين مقدار رس و قـابليـت هدايت الكتريكى در خاكهاى مورد مطالعه اين فرضيه را تأييد مى كند. در
مىرسد اين فاكتور، عامل محدود كنندهاى براى جوانهزنى، رشد

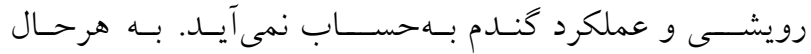
همانطوركه در جدول ( (1) مشـاهده مىشـود تفاوت معنىدارى رلى در ويزگ كهاى خاى بين افت سطحى و زيرسطحى وجود ندارد. براساس جدول (Y) ارتباط مثبت و معنىدارى بين مقدار شورى و بافت خاك بهدسـت آمد. در واقع با رسسىشدن بافت خاك و كـاهش مقدار شــن، شـــورى خاك هم افزايش مىيابد كه اين مى تواند بهدليل نفوذيذيرى كم خاكهاى رسسى و در نتيجه عدم آبشويى كافى املاح محلول در اين خاكها باشد.

ب) شكلهاى مختلف يتاسيم در خاكهاى مورد مطالعه مقـدار رتـاســيم محلول در خـاكهاى مورد مطالعه در افقهاى سـطحى به Vo ميلى گرم بر كيلو گرم و در خاكهاى زيرسـطحى به ه9 ميلى گرم بر كيلو گرم مىرسد ولى اختلاف معنى دارى بين

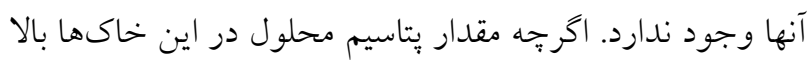
مىباشد اما اين مقدار در دامنه مقدار پِّاسيم محلول گزارششده توسط نجفى قيرى و همكاران (1) براى خاكهاى استان فارس 
جدول r. ضريب همبستخى بين ويرٔى هاى خاك و شكل هاى پِاسيم

\begin{tabular}{|c|c|c|c|c|c|c|c|c|c|}
\hline يتاسياع & غيت تِّاسيم & تِّاديم & مِّاسيم & ظرفيت & هابليت & كربنات كلسيم & شن & سيلت & ويزگكى ها \\
\hline$\circ / V^{* *}$ & $\circ / \wedge Q^{* *}$ & $\circ / \Lambda I^{* *}$ & $\circ / \mu_{0}^{*}$ & $\circ / \Lambda \circ^{* *}$ & o & $-0 / Y Y$ & $-\circ / \wedge \varsigma^{* *}$ & $\circ / T \wedge$ & رس \\
\hline $0 / 10$ & $0 / T Q$ & $0 / 14$ & $\circ / \wedge$ & -o/०Y & $0 /\left.4\right|^{* *}$ & $0 / T Q$ & $-\circ / V^{* * *}$ & 1 & سيلت \\
\hline$-\circ / \Delta V^{* *}$ & $-\circ / V^{* *}$ & $-0 / 90^{* *}$ & $-0 / 1 \mathrm{~V}$ & $-0 /\left.0\right|^{* *}$ & $-\circ / \mathbb{Y} Q^{* *}$ & $\circ / 0 Y$ & 1 & & شن \\
\hline$-\circ / \mathcal{F}_{0} * *$ & $-0 / \mathbb{*} Q^{* *}$ & $-0 / 44 * *$ & $-\circ / \Delta \varphi^{* *}$ & $-0 /\left.0\right|^{* *}$ & س & 1 & & & كربنات كلسيم \\
\hline$\circ / \circ \Delta$ & $0 / 19$ & س & $\circ / \circ \Delta$ & $\circ / \circ \mu$ & 1 & & & & هدايت الكتر يكىى \\
\hline$\circ / 09^{* *}$ & $0 / 99^{* *}$ & $\circ / V Q^{* *}$ & $0 / 9 Y^{* * *}$ & 1 & & & & & ظرفيت تبادل \\
\hline$\circ / 9 Q^{* *}$ & $\circ / \Delta \wedge^{* *}$ & $\circ / \Delta \Delta^{* *}$ & 1 & & & & & & يتاسيم محلول \\
\hline$\circ / 9 V^{* *}$ & $\circ / \Lambda V^{* *}$ & 1 & & & & & & & يّاسيم تبادلى \\
\hline $0 / 9 r^{* *}$ & 1 & & & & & & & & غيرتباديم \\
\hline
\end{tabular}

**، **: بهترتيب معنى دار در سطح هو ا درصد با آزمون دانكن

در خاكهاى سـطحى باشد (1)). نجفى قيرى و همكاران (1/) مقدار يُتاسـيم تبادلى را در خاكهاى اســان فارس در افقهاى

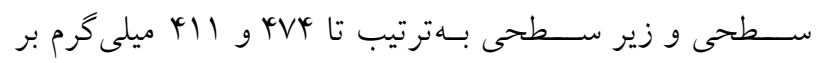
كيلوگرم گزارش كردند. يتاسيم تبادلى ارتباط مثبت و معنى دارى بـا مقدار رس و ظرفيت تبادل كاتيونى و ارتباط منفى با كربنات كلسـيم معادل و شـن داشـت كه البته با نتايج تحقيقات سـاير

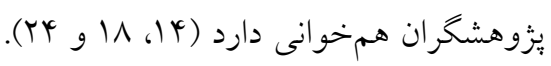
يتاسيم غيرتبادلى كه شكل به كندى قابل استفاده يتاسيم براى كياه اسـت نيز در خاكهاى سـطحى و زير سـطحى بهترتيب از A مى كند و تفاوتى بين خاكهاى ســطحى و زير ســطى وجود ندارد. ارتباط مثبت و معنىدارى بين يُّاســيم غيرتبادلى و مقدار رس و ظرفيت تبادل كاتيونى بهدست آمد در حالىكه اين ارتباط با مقدار شن و كربنات كلسيم معادل منفى و معنى دار بود. ارتباط
حقيقت در خاكهايى كه يتانسـيل آبشـويى كمتر است بهدليل تعادل بين شـكل هاى يّاسـيم، مقدار شـكل هاى مختلف يُّاسيم

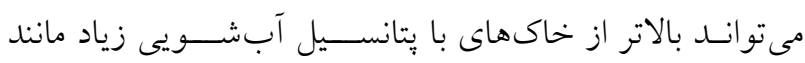

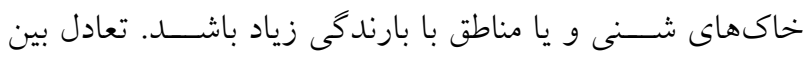
شـكل هاى يتاسيم را مىتوان از ارتباط مثبت و معنى دار بهدست آمده بين اين شكل ها در جدول (Y) تأييد كرد. يتاسـيم تبادلى كه مانند يتاســيم محلول شــكل به ســهولت

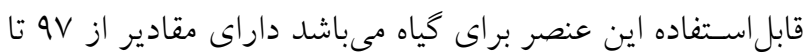

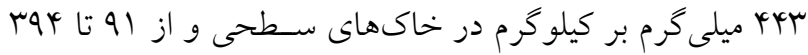
ميلى گرم بر كيلو گرم در خـاكهاى زيرســـــى بود. خاكهاى سـطحى داراى مقدار پيتاسـيم تبادلى بيشترى نسبت به خاكهاى زيرسطحى بودند كه اين مىتواند بهدليل امكان هواديدكى بيشتر كانىهاى يتاسيمدار در خاكهاى سطحى و همجينين اضافه شدن كودهاى حاوى يُاسـيم و مواد آلى كه سـرشار از يتاسيم هستند 
درصسـ (ميانخين شب/ه درصسد) از وزن دانه را يتاسـيم به خود

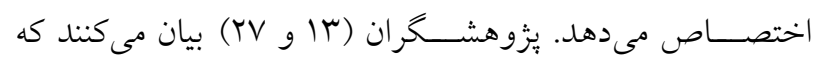
مقدار يتاسـيم موجود در دانه رسـيده گُندم صـرفنظر از مقدار يتاسـيم خاى و تيمارهاى كودى يتاسـيم حدود ب/ه درصسـ از وزن خشـى مىباشد و افزايش يتاسيم خاك فقط سبب افزايش يتاسـيم در قسـمت هاى رويشسى كياه مىشـود كه البته با نتايج بهدست آمده مطابقت ندارد. اخر جهه ارتباط معنى دارى بين مقدار يتاسـيم دانه گندم و شـكل هاى يتاسـيم بهدسـت نيامد اما براى خاكهاى بافت ريز (رس >مب درصــ) نشان داده شد كه مقدار

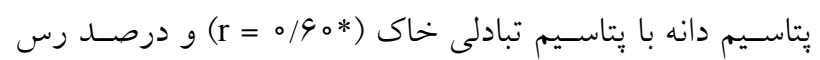

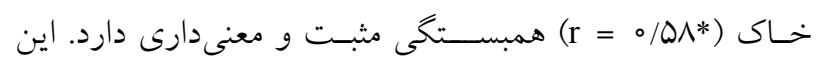
بدانمعنى اســت كه براى خاكهاى ســـــين اســـات آمونيم مىتواند عصسارهذير مناسبى جهت تخمين وضعيت يتاسيم خاى و مقدار يتاسـيم قابل استفاده گياه در منطقه مورد مطالعه باشد. از طرف ديخر، آنـاليز رگرســيون گام به گام نشـــان داد كه مقدار يتاســيم دانه كندم ارتباط با مقدار رس و بِ-هاش خاك دارد [Seed K= -VQr+॰D०Y(Clay) + I Ir(pH)] رس و بֶ-هاش خاك مىتوان مقدار يتاسيم جذبشهده بهوسيله كَياه را تخمين زد كه اين مىتواند در توصـيه مصـرف كودهاى يتاسيم حائز اهميت باشد. بههرحال ذكر اين نكته ضرورى است كـه اين نتـايج را نمى توان بـهـ ســاير مناطق تعميم داد و بهنظر مىرســـد كه تغيير در عواملى مانند وضــعيت رزيم رطوبتى و

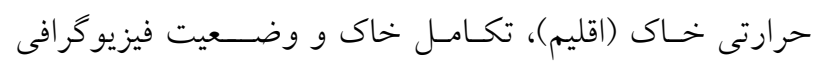

اراضى و نوع مواد مادرى مىتواند حائز اهميت باشد (1) (1).

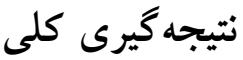

بـهنطوركلى مىتوان نتيجـهـ گيرى كرد كـه اغلـب خاكهاى مورد مطالعه در زمان برداشت كندم هنوز داراى مقادير كافى بتاسيم به شكل هاى مختلف مىباشند و تعادل بين شكل هاى يتاسيم نيز در اين زمان همجهنان وجود دارد. همجينين با افزايش مقدار رس در خاكها مقادير همه شـــلهل هاى يتاســيم افزايش مى يابد كه اين مىتواند اهميت بافت خاى را در بيشبينى وضعيت حاصلخيزى
معنى دار بهدسـت آمله بين شكل هاى مختلف يتاسيم (جدول r) نشـانكر اين موضسوع مىتواند باشـــ كه اين شـكلهـا در مرحله

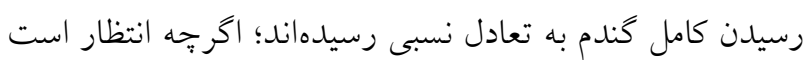
كه در مراحل پِيانى رشد كُندم از مقدار يتاسيم محلول و تبادلى

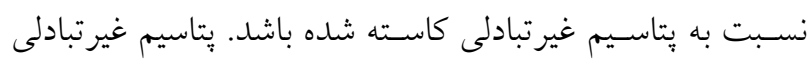
يكى از شــكل هاى مهم يتاســيم بوده و در دراز مدت مىتواند

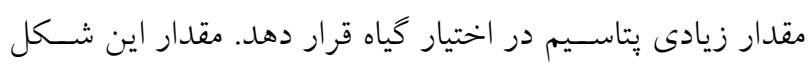
يتاسـيم معمولاً بيشـتر از يتاسيم محلول و تبادلى بوده اما قابليت

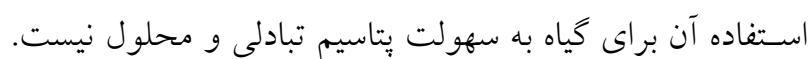
در واقع با جذب يتاسـيم محلول و تبادلى بهوسـيله ريشه گياه و كاهش مقدار آن در خاك، بتاسـيم غيرتبادلى در طول زمان آزاد

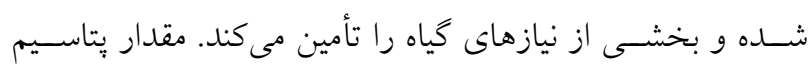

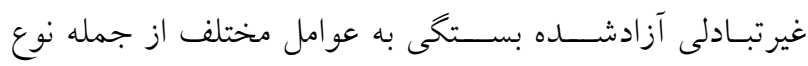
كانى هاى بخش رس، تكامل خاك و ساير ويزگ هاى هيز فيكى و

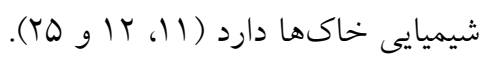
درصد اشباع يتاسيم در خاكهاى مورد مطالعه از T/9 تا ك/ 9

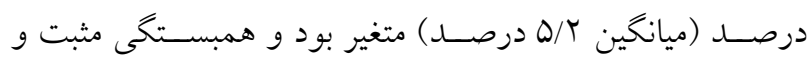
معنى دار با مقدار رس، ظرفيت تبادل كاتيونى و شكلهاى يتاسيم و ارتباط منفى با درصــ شـن و كربنات كلسـيم معادل داشـت (جدول r). مقادير بهدست آمده براى درصد اشباع يتاسيم موافق نتايج نجفى قيرى و همكاران (1/) براى خاكهاى ايران و بسيار بـالاتر از نتـايج الزبيـدى و همكـاران (ه) براى خــاكهاى لبنان مىباشد.

ج) ارتباط درصد يُاسيم دانه گندم با شكلهاى يتاسيم خاك يزوهشــــران عصــاره خيرهـاى متعددى را جهـت يافتن ارتباط يتاسـيم خاك و يتاســيم جذبـشـــه بهوسـيله گياه و در نتيجه شـناسايى خاكهاى دجّار كمبود يتاسيم بِيشنهاد كردهاند كه البته عمده اين يزوهش ها در شــرايط كلخانه و براى خاكهاى متنوع انجـام شـــده و قـابـل تعميم به محيط مزرعه و همه نوع خاى

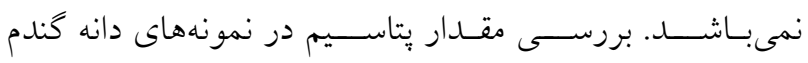

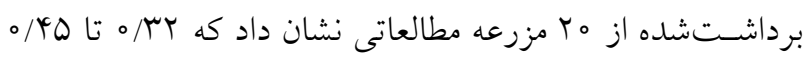




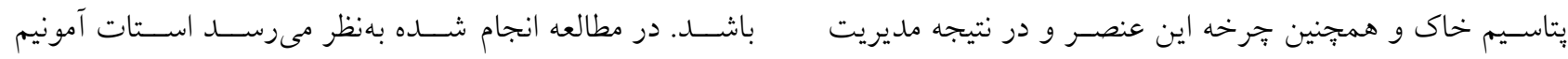

$$
\begin{aligned}
& \text { حاصلخيزى آن مورد توجه قرار دهد. نتايج اين تحقيق نشان داد عصساره گير مناسـبى براى تعيين وضسعيت بتاسـيم در خاكهاى } \\
& \text { كه توانايى عصـاره گيرهاى مختلف يتاسـيم ممكن است حتى در بافت ريز باشد. } \\
& \text { يك مقياس جغرافيايى كو جك نيز براى بعضى خاكها ضـعيف }
\end{aligned}
$$

\section{منابع مورد استفاده}

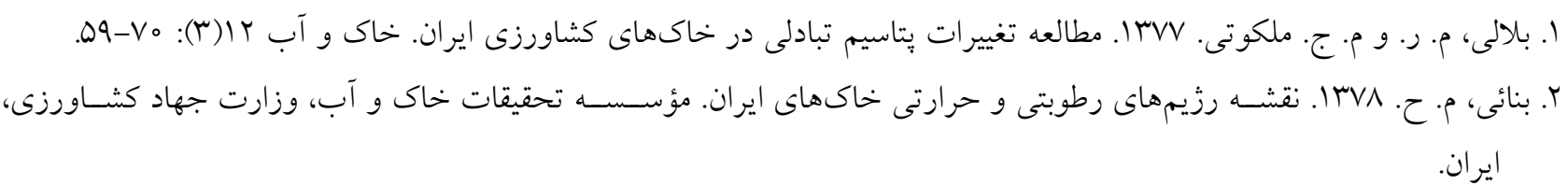

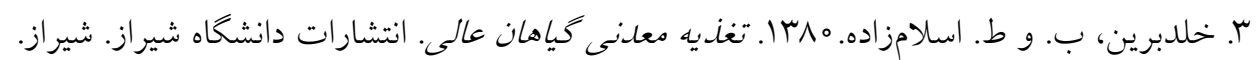

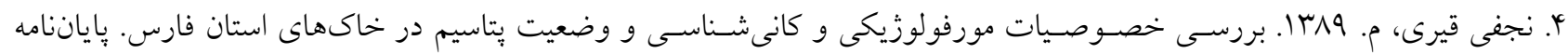

$$
\text { دكترى بخش علوم خاك، دانشكده كشاورزى، دانشخاه شيراز. }
$$

5. Al-Zubaidi, A., S. Yanni and I. Bashour. 2008. Potassium status in some Lebanese soils. Lebanese Sci. J. 9(1): 81-97.

6. Chapman, H. D. 1965. Cation exchange capacity. PP. 891-901. In: Black, C.A. (Ed.), Methods of Soil Analysis. Part 2. America Society of Agronomy, Madison, WI.

7. Gregory, P., D. Crawford and M. McGowan. 1979. Nutrient relations of winter wheat: 1. Accumulation and distribution of Na, K, Ca, Mg, P, S and N. The J. Agric. Sci. 93(2): 485-494.

8. Havlin, J. L., J. D. Beaton, S. L. Tisdale, and W. L. Nelson. 1999. Soil fertility and fertilizers. Prentice-Hall International (UK) Limited, London.

9. Helmeke, P. A. and D. L. Sparks. 1996. Methods of soil analysis, Part 3: Chemical methods. American Society of Agronomy, Madison, WI.

10. Mass, E.V. and G. J. Hoffman. 1977. Crop salt current assessment. J. Irrig. Drainage Div. 103(2): 115-134.

11. Mengel, K. and Rahmatullah. 1994. Exploitation of potassium by various crop species from primary minerals in soils rich in micas. Biol. Fertil. Soils, 17: 75- 79.

12. Mengel, K. and K. Uhlenbecker. 1993. Determination of available interlayer potassium and its uptake by ryegrass. Soil Sci. Soc. Am. J. 57: 561-566.

13. Merbach, W., J. Garz, W. Schliephake, H. Stumpe, and L. Schmidt. 2000. The long-term fertilization experiments in Halle (Saale), Germany — introduction and survey. J. Plant Nutr. Soil Sci. 163: 629-638.

14. Nabiollahy, K., F. Khormali, K. Bazargan and S. Ayoubi. 2006. Forms of K as a function of clay mineralogy and soil development. Clay Miner. 41: 739-749.

15. Najafi-Ghiri, M., A. Abtahi, F. Jaberian and H. R. Owliaie. 2010. Relationship between soil potassium forms and mineralogy in highly calcareous soils of southern Iran. Aust. J. Basic. Appl. Sci. 4(3): 434-441.

16. Najafi-Ghiri, M., A. Abtahi, and F. Jaberian. 2011. Factors affecting potassium release in calcareous soils of southern Iran. Soil Res. 49(6): 529-537.

17. Najafi-Ghiri, M., A. Abtahi, N. Karimian, H. Owliaie and F. Khormali. 2011. Kinetics of non-exchangeable potassium release as a function of clay mineralogy and soil taxonomy in calcareous soils of southern Iran. Arch. Agron. Soil Sci. 57(4): 343-363.

18. Najafi-Ghiri, M., A. Abtahi, H. R. Owliaie, S. S. Hashemi and H. Koohkan. 2011. Factors affecting potassium pools distribution in highly calcareous soils of southern Iran. Arid Land Res. Manage. 25: 313-327.

19. Natarajan, S. and A. Renukadevi. 2003. Vertical distribution of forms of potassium in major soil series of Tamil Nadu. Acta Agronomica Hungarica 51(3): 339-346.

20. Nelson, D. W. and L. E. Sommers. 1982. Total carbon, organic carbon and organic matter. PP. 539-579. In: Page, A. L. (Ed.) Methods of Soil Analysis, Part 2. American Society of Agronomy, Madison, WI.

21. Rowell, D. L. 1994. Soil Science: Methods and applications. Longman Scientific and Technical, UK.

22. Salinity Laboratory Staff. 1954. Diagnosis and Improvement of Saline and Alkali Soils. Handbook No. 60. United States Department of Agriculture Washington, D.C.

23. Sharpley, A. N. 1989. Relationship between potassium forms and mineralogy. Soil Sci. Soc. Am. J. 52: $1023-1028$.

24. Sinha, A. K. and S. Biswas. 2003. Distribution of different forms of potassium in surface and subsurface horizons of 
نشريه علوم آب و خاك (علوم و فنون كشاورزى و منابع طبيعى) / سال بيستم / شماره هفتادو هفتم/ باييز ههr|

some well established soils of West Bengal under the order Inceptisols. J. of Interacademicia 7(3): 286-291.

25. Sparks, D. L. 2000. Bioavailability of soil potassium. PP. 38-53. In: Sumner, M. E. (Ed.), Handbook of soil science. CRC Press: Boca Raton, FL.

26. Sparks, D. L. and P. M. Huang. 1985. Physical chemistry of soil potassium. PP. 201-276. In: Munson R. D. (Ed.), Potassium in Agriculture. American Society of Agronomy, Madison, WI.

27. Zorb, C., M. Senbayram and E. Peiter. 2014. Potassium in agriculture-status and perspectives. J. of Plant Physiol., 171(9): 656-669. 


\title{
Potassium Status in Wheat-cultivated Soils and its Relationship with Grain K in Darab Region, Southeastern Fars Province
}

\author{
M. Najafi-Ghiri
}

(Received: April 5-2015; Accepted : May 8-2016)

\begin{abstract}
The status of soil $\mathrm{K}$ forms and its relationship with $\mathrm{K}$ content in wheat grain at harvest period may be important for nutrient fertility management. For this purpose, 40 surface $(0-20 \mathrm{~cm})$ and subsurface $(20-40 \mathrm{~cm})$ soil samples and also grain samples from wheat fields of Darab region were randomly sampled in 2014. Then physicochemical properties of the soils and the contents of soluble, exchangeable and non-exchangeable $\mathrm{K}$ and contents of $\mathrm{K}$ in wheat grains were determined. Results indicated that content of soluble, exchangeable and non-exchangeable $\mathrm{K}$ in the studied soils ranged 15-70, 91-443 and 396-1182 $\mathrm{mg} \mathrm{kg}^{-1}$, respectively. Significant relationships were obtained between soil $\mathrm{K}$ forms and clay, calcium carbonate and CEC. Although it is expected that content of easily available K (soluble and exchangeable K) was low at late stage of wheat growth, most soils had sufficient $\mathrm{K}$ content. The positive and significant relationship among different $\mathrm{K}$ forms was indicative of the $\mathrm{K}$ forms equilibration at the time of wheat harvesting. Although there is not a relationship between $\mathrm{K}$ content in wheat grain and soil $\mathrm{K}$ forms, it was shown that $\mathrm{K}$ content of wheat grain was correlated with soil exchangeable $\mathrm{K}$ and clay content in fine-textured soils (clay $>30 \%$ ). It means that ammonium acetate may be a suitable extractant for estimation of soil $\mathrm{K}$ status and plant available $\mathrm{K}$ of heavy-textured soils in the studied region.
\end{abstract}

Keywords: Ammonium acetate, Calcareous soils, Exchangeable K, Wheat grain K

1. Dept. of Range and Watershed Manage., College of Agr. and Natural Resources of Darab, Shiraz Univ., Darab, Iran.

*: Corresponding Author, Email: mnajafighiri@yahoo.com 